\title{
The Evolution of Smoking and Intoxicant Plant Use in Ancient Northwestern North America
}

\author{
William J. Damitio (D), Shannon Tushingham, Korey J. Brownstein, R. G. Matson, and David R. Gang
}

Smoking pipes discovered in archaeological contexts demonstrate that Indigenous peoples of the Pacific Northwest of North America have practiced smoking for over 4,500 years. Archaeometry and ancient residue metabolomics provide evidence for the association of particular plants with these artifacts. In this article, we synthesize recent research on ancient smoking and present current knowledge on the spatiotemporal distribution of smoking in the past. The presence of stone smoking pipes in the archaeological record is paired with our understanding of past plant use based on chemical residue analyses to create a picture of precontact smoking practices. Archaeological pipe data demonstrate that smoking was a widely distributed practice in the inland Northwest over the past several thousand years, but not on the coast. Distributional data-including positive and negative evidence from chemical residue studies-show that tobacco was an important smoke plant in the region as early as around 1,410 years ago and as far north as the mid-Columbia region. Ancient residue metabolomics contributes to a richer understanding of past use of specific plants through the identification of tobacco species and other indigenous plants, including Rhus glabra, Cornus sericia, and Salvia sp., as contributing to the chemical residues in ancient pipes.

Keywords: residue analysis, smoking, tobacco, Pacific Northwest, Northwest Plateau, ancient residue metabolomics, biomolecular archaeology

Las pipas para fumar encontradas en contextos arqueológicos demuestran que los pueblos indígenas del Noroeste Pacífico de Norteamérica han fumado desde hace 4,500 años. La arqueometría y la metabolómica de residuos antiguos arrojan evidencia para la asociación de ciertas plantas con estos artefactos. En este artículo, sintetizamos investigaciones recientes y presentamos el estado de conocimiento acerca de la distribución espacial y temporal de la práctica del fumar en el pasado. La presencia de pipas de fumar, hechas de piedras, en el registro arqueológico se junta con nuestro entendimiento del uso de plantas en el pasado basado en análisis de residuos químicos para así crear un panorama de las prácticas de fumar antes del Contacto europeo. Los datos de pipas arqueológicas demuestran que el fumar fue una práctica ampliamente distribuida en la región interior del Noroeste a lo largo de varios miles de años, pero que esto no fue así en la costa. Datos de distribución -incluyendo evidencia positiva y negativa de estudios de residuos químicos-señalan que el tabaco fue una planta de fumar importante en la región ya hace cerca de 1,410 años y tan al norte como la zona intermedia del río Columbia. La metabolómica de residuos antiguos contribuye a un entendimiento más copioso del uso de plantas específicas en el pasado a través de la identificación de especies de tabaco y otras plantas indígenas, incluyendo Rhus glabra, Cornus sericia y Salvia sp., como contribuyentes de los residuos químicos en pipas antiguas.

Palabras clave: análisis de residuos, fumar, tabaco, Noroeste Pacífico, Meseta del Noroeste, metabolómica de residuos antiguos, arqueología biomolecular

William J. Damitio (william.damitio@ wsu.edu, corresponding author*) and Shannon Tushingham a Department of Anthropology, Washington State University, PO Box 644910, Pullman, WA 99164-4910, USA

Korey J. Brownstein and David R. Gang $\square$ Institute for Biological Chemistry, Washington State University, PO Box 646340, Pullman, WA 99164-6430, USA

R. G. Matson घ Department of Anthropology, University of British Columbia, 6303 NW Marine Drive, Vancouver, British Columbia, V6T 1Z1, Canada

*The corresponding author e-mail has been corrected since the article's initial publication. See DOI:10.1017/aaq.2021.83.

American Antiquity 86(4), 2021, pp. 715-733

Copyright (C) The Author(s), 2021. Published by Cambridge University Press on behalf of the Society for American Archaeology. This is an Open Access article, distributed under the terms of the Creative Commons Attribution licence (http://creativecommons.org/licenses/by/4.0/), which permits unrestricted re-use, distribution, and reproduction in any medium, provided the original work is properly cited.

doi:10.1017/aaq.2021.39 
$\mathrm{T}$ The use of psychoactive plants to induce a variety of physiological effects, including altered states of consciousness, appears to be a nearly universal human tendency with potentially deep coevolutionary roots (Hagen and Tushingham 2019). Researchers have suggested that at least some toxic plant use evolved in primates to self-medicate against a variety of parasites and other infections, causing primates to experience consciousness-altering effects as an accidental side effect (Hagen et al. 2009, 2013). Humans take a more active approach, deliberately harnessing the cognitive performance-enhancing properties of many psychoactive plants-those containing nicotine and caffeine (Einöther and Giesbrecht 2013; Sullivan et al. 2008)—which may themselves represent an evolved response on the part of the psychoactive plant (Hagen and Tushingham 2019; Hagen et al. 2009; Rezvani and Levin 2001). Cultures throughout the world have utilized both profoundly psychoactive plants (e.g., datura or various psychotropic mushrooms) and milder substances (e.g., tobacco or plant-derived ethanol), which are taken in heavy doses to induce highly altered states of consciousness, for thousands of years (Furst 1972; Schultes et al. 2001; VanPool 2009).

There are also strong, highly specific cultural norms regulating the use of psychoactive substances-plant-derived or synthesized. In traditional, nonindustrial societies, the use of psychoactive substances as entheogens may be limited to ritual specialists (i.e., shamans or traditional medical practitioners) or to individuals undergoing rites of passage (VanPool 2009). Other psychoactive plants, or the same plant used in different ways or concentrations, might be taken more casually as medicine or for recreation, although often with other kinds of limitations based on age, gender, or social status (Hagen et al. 2016). Archaeologists are contributing to understanding this human predilection by exploring both the human-plant relationships that developed in the past as well as the material cultures that developed around the use of psychoactive plants.

As people have experimented with a wide range of psychoactive substances, they have also developed a variety of methods and implements to facilitate the ingestion of intoxicant plants and to enhance their physiological effects. Perhaps the most important element of this material culture is the "delivery system," which enables a person to transform a plant into drug. Smoking is a typical means of doing so, but even this method allows for many different approaches. In the southern Coastal and Inland Pacific Northwest of North America, stone - and to a lesser extent, clay-smoking pipes provide the clearest evidence that peoples of the region have been smoking for over 4,500 years, as evidenced by the oldest stone pipes collected in the region from a cache in the central Columbia Plateau (Galm and Komen 2012).

Elsewhere in the Americas, however, researchers have documented a wide variety of artifacts associated with the ancient use of tobacco and other intoxicants, including storage vessels (Zagorevski and Loughmiller-Newman 2012); cups, bowls, and larger vessels used for preparation and consumption (LoughmillerCardinal 2018; Milanich 1979); enema tubes (Carod-Artal 2015; Seinfeld 2018); and snuff trays and tubes (Torres 1996).

In this article, we focus on stone smoking pipes, taking a multiproxy approach to explore traditional smoking practices among the Native peoples of the Pacific Northwest. We test the hypothesis that precontact use followed the same distribution documented by early twentieth-century ethnographers (Gunther 1973; Kroeber 1941; Setchell 1921; Teit 1900, 1909) and others (Douglas 1914) - that is, that people smoked throughout the region, except in its farthest northern areas, and that tobacco in particular was smoked along the southern Northwest Coast and the central Northwest Plateau, but that it was absent in the southern Columbia Plateau. We consider how smoking practices have changed or been maintained by Native groups through time, as well as the shortcomings of reliance on the ethnographic record to reflect the realities of contemporary practices and those that may be considered "traditional" in the near or distant past.

Following an examination of the ethnohistoric record, we present findings from a database of stone smoking pipes compiled from published and gray literature from the region, as well as 
Table 1. Species Compared to Archaeological Pipe Extracts.

\begin{tabular}{lllll}
\hline \multicolumn{2}{c}{ Ethnographically Utilized Native Species } & & Other Species \\
\cline { 1 - 1 } Scientific Name & Common Name & & Scientific Name & Common Name \\
\hline Artemisia ludoviciana & silver wormwood & & Lobelia inflate & puke weed \\
Arctostaphylos uva-ursi & bearberry/kinnikinnick & & Nicotiana glauca & tree tobacco \\
Cornus sericea & red osier dogwood & & Nicotiana obtusifolia & desert tobacco \\
Gaultheria shallon & salal & Nicotiana rustica & wild tobacco \\
Nicotiana attenuata & coyote tobacco & & Nicotiana tabacum & commercial tobacco \\
Nicotiana quadrivalvis & Indian tobacco & & Salvia sonomensis & Sonoma sage \\
Rhus glabra & smooth sumac & Verbascum thapsus & common mullein \\
Taxus brevifolia & Pacific yew & & \\
\hline
\end{tabular}

the more direct investigation of archaeological site collections themselves. This research reveals references to the presence of pipes or pipe fragments at 60 sites throughout the Pacific Northwest, as well as 56 artifacts from 26 sites whose collections are held at the Washington State University Museum of Anthropology (Damitio 2018). Finally, we present the results of chemical residue analyses, both published (Tushingham et al. 2013, 2018) and previously unpublished. Improved extraction methodologies and ancient residue metabolomics techniques developed by Brownstein and colleagues (2020) have been applied to a large sample of archaeological materials from western North America. Understanding the spatial distribution of these results, both positive and negative, allows us to understand ancient tobacco use in the region.

Our efforts have yielded compelling evidence that smoking tobacco and other plants has been important in the lives of Inland Northwest peoples for thousands of years. Tobacco was not the only smoke plant used both ethnohistorically and, as chemical evidence demonstrates, in the deeper past. Arctostaphylos uva-ursi (kinnikinnick, or bearberry) has been identified ethnographically as an important plant smoked in both the Coastal and Inland Northwest to produce a narcotic effect (Gunther 1973:44; Kroeber 1941). Plants such as Rhus glabra, species of Cornus, Taxus brevifolia, and others (Table 1) were also smoked where available throughout the region. The results not only reveal the time depth of human interest in psychoactive plants in general but also reflect the durability of particular human-plant relationships through the longue durée.

\section{Ethnohistoric Smoking}

The Pacific Northwest of North America is a geographically and culturally diverse region traditionally divided into two distinct culture areas: the Northwest Coast and the Plateau. The region extends thousands of kilometers from northern California to southeastern Alaska. Major river systems, including the Fraser and Columbia and their tributaries, connected peoples throughout the region. Bearing this in mind, the ethnohistoric record enables us to make some generalizations about smoking in the Northwest.

Kroeber (1941) produced a summary of tobacco and smoking data that revealed a great deal of variability across the Pacific Northwest with regard to whether Native people smoked and, if so, whether tobacco was among the plants in use (Figure 1). Kroeber's picture should be considered a flawed and incomplete overview at best; however, it distills a great deal of roughly contemporaneous ethnographic data demonstrating at the very least that smoking was a nearly universal practice in the Pacific Northwest from the Oregon coast to the Northern Fraser Plateau in present-day British Columbia (Kroeber 1941). Farther north, Haida and Tlingit were recorded as having grown and chewed some plant-later found to be Nicotiana quadrivalvis (Turner and Taylor 1972)—mixed with lime derived from marine shell.

In the Plateau and on the Northwest Coast, plants were smoked alone or as part of a mixture of plants (Table 1; Kroeber 1941). Arctostaphylos uva-ursi was often an element of smoking mixtures in the Interior and Coastal Northwest 


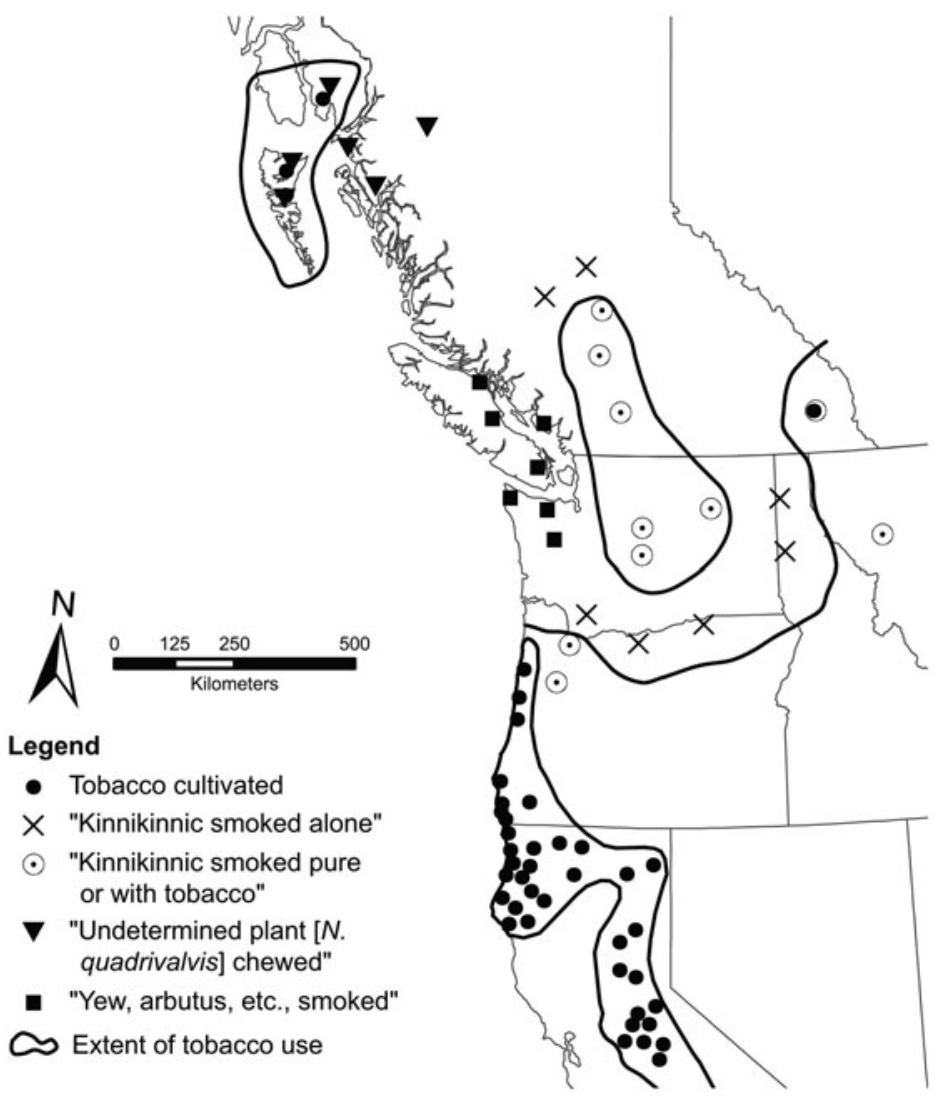

Figure 1. Partial adaptation of Kroeber 1941, Maps 8 and 9. This map illustrates Kroeber's summary of data related to smoking and tobacco planting among western North American Native groups at that time.

following contact, as was Taxus brevifolia (Pacific yew) on the coast (Gunther 1973:44; Taylor and Taylor 1981). Teit (1909:574-576; Turner 2014:213), however, suggests that the practice of mixing kinnikinnick with tobacco came only after the introduction of EuroAmerican trade tobacco, which was perceived - among the Secwepemc (Shuswap), at leastto be stronger than the native varieties. Writing earlier in the nineteenth century, Douglas (1914) makes no note of any mixing of other plants with native tobaccos in the southern Columbia Plateau, although he does indicate that A. uva-ursi was smoked alone.

We have given particular attention to $A$. uva-ursi in our residue studies because it is so often mentioned specifically as an important smoke plant by early twentieth-century ethnographers as either an element in mixes with tobacco or a smoke plant in its own right. Understanding the relationship between A. uva-ursi and tobacco smoking in the more distant past may help to untangle the sometimes contradictory information given to us regarding kinnikinnick use through the ethnohistoric record.

\section{Tobacco in the Pacific Northwest}

The genus Nicotiana (family: Solanaceae) includes a number of species of leafy herbs and shrubs. The presence of the psychoactive alkaloid nicotine in the leaves of Nicotiana species has made tobaccos plants of interest for peoples around the world. Several species, including the hybrid $N$. tabacum used in the production of modern commercial tobacco products, are indigenous to the Americas, with the ultimate origins of most species lying in South America (Goodspeed 1954). Although the Pacific Northwest is at the northern limit of the natural range of the genus, two species- $N$. attenuata (coyote 
tobacco) and $N$. quadrivalvis (Indian tobacco; syn: $N$. bigelovii) —were in the region before contact, and both are important to Indigenous peoples of the Plateau and Northwest Coast.

Kroeber (1941) reports that a large area from the central Columbia Plateau through the Fraser Plateau is populated by groups who traditionally smoked tobacco. The Columbia Plateau to the south and east of this area was supposedly without traditional tobacco use (but see Tushingham et al. 2018). This is summarized by Kroeber (1941) in his Map 8, reproduced in part here (Figure 1). In the Pacific Northwest outside of the Plateau, there is more variability in the use of tobacco. West of the Cascade Range and north of the Columbia River, no coastal peoples included in the survey indicated that they traditionally smoked tobacco. Instead, coastal peoples smoked a variety of other plants, including T. brevifolia needles, A. uva-ursi leaves, and others (Gunther 1973; Kroeber 1941). Given the profound effects of contact on Indigenous practices, it is difficult to say with complete confidence that coastal peoples never used tobacco. Furthermore, the lack of a durable material culture associated with smoking on the coast (Gunther 1973:35; Turner 1998:163-164) limits the potential for relevant material culture to preserve archaeologically.

The two tobaccos native to the region, $N$. attenuata and $N$. quadrivalvis, have distinct, but overlapping, distributions. The former species is endemic to the Plateau, occurring wild and under cultivation as far north as Secwepemc country in southern-central British Columbia (Teit 1909), whereas the current natural range of the latter extends only as far north as central Oregon (Goodspeed 1954; Hammet 2000; Turner and Taylor 1972; Winter 2000). Both species were used in different contexts by various peoples of the Plateau. Except for chewing of $N$. quadrivalvis among the Haida and Tlingit (Turner and Taylor 1972), we could not find any references indicating tobacco cultivation or use on the coast north of the mouth of the Columbia River.

For the Pacific Northwest peoples who used tobacco, it was regarded as a sacred and powerful plant that could serve in recreational, ceremonial, and medicinal roles. Early interactions between
Natives and non-Natives in the Pacific Northwest were often punctuated by the trading or sharing of tobacco (Douglas 1914). In these cases, smoking (of tobacco, at least) is an activity that signaled and reinforced positive interpersonal relationships and doubled as a means of conflict resolution. Other perspectives, including those drawing on present-day discussions with Indigenous people, emphasize the sacred nature of tobacco and the durability of its importance to Native communities (Phillips 2016; Snyder 2016). Tobacco is frequently singled out as having supernatural origins by Interior Northwest peoples. For example, Keddie (2016) citing (Teit 1900:309) notes that Syilx (Okanagans) would smoke ceremonially before all "serious undertakings." Likewise, Turner (2014:213) explains that for a number of interior peoples "all councils and many feasts began with smoking ceremonies." This practice is continued today as what Turner (2014:214) identifies as part of "routine rituals of respect for the spirits . . that provide for the people."

\section{Previous Research}

In his seminal article, Rafferty (2002) demonstrated the utility of chemical residue analysis to test archaeological pipe contents from the northeastern United States for compounds associated with tobacco. Researchers have since used chemical analyses to study the ancient use of tobacco and other intoxicants in regions throughout the Americas. For example, Carmody and colleagues (Carmody, Davis, et al. 2018; Carmody, Kassabaum, et al. 2018) have identified nicotine in stone pipes from two sites in the southeastern United States. In Chile, researchers have detected nicotine in ancient human hair, pipes, and other artifacts (Echeverría and Niemeyer 2013; Echeverría et al. 2014; Niemeyer et al. 2018). Nicotine has likewise been identified in small ceramic vessels of the late Mayan period in Mesoamerica (Zagorevski and Loughmiller-Newman 2012).

In northwestern North America, the earliest tobacco residue study examined the carbonized contents of several steatite pipe bowls from the Keatley Creek site (EeRl-17) in British Columbia. Hayden (2000) detected no nicotine in the 
samples tested. No further work evaluating chemical residues associated with Pacific Northwest stone pipes was performed until Tushingham and colleagues (2013) identified nicotine in six precontact pipes and pipe fragments from the northern California coast. Following Rafferty (2002, 2006) and Rafferty and colleagues (2012), Tushingham and colleagues (2013) analyzed their samples using gas chromatographymass spectrometry but developed a method whereby artifacts were soaked in a chemical solvent and sonicated, permitting the extraction of residues from the matrix of stone and clay pipes rather than from charred organic material associated with the pipes. These methods were developed further in a multiyear study funded by National Science Foundation-Archaeometry (Brownstein et al. 2020), and they were applied in a 2018 study by Tushingham and colleagues that found nicotine to be associated with artifacts from three precontact sites in southeastern Washington state.

Previous biomolecular studies resulted in the identification of nicotine in pipes and pipe fragments from sites in the southern Columbia Plateau (Tushingham et al. 2018), as have studies from the southern Northwest Coast (Tushingham et al. 2013). Farther south on the California coast, Eerkens and colleagues (2018) have identified nicotine in ancient human dental calculus. These studies have confirmed what is suggested by the ethnohistoric record: that tobacco was used by Pacific Northwest peoples prior to the arrival of Euro-Americans. Below, we discuss the results of previously unpublished residue studies that further expand the spatial and temporal scope of such analyses in the region.

\section{Methods and Materials}

To test hypotheses outlined in this study, we took an interdisciplinary approach that similarly draws from varied methods and sources. The study includes an updated synthesis of published and unpublished data on the distribution of pipes in the region originally compiled by Damitio (2018), and chemical and ancient residue metabolomics studies of a sample of these archaeological pipes. All previously unpublished results presented in this article were obtained following new methodology detailed by
Brownstein and colleagues (2020) using liquid chromatography-mass spectrometry (LC-MS).

\section{Artifact Distribution Analysis}

To explore the precontact distribution of smoking across time and space, we synthesized data from (1) a review of published and gray literature, (2) an exploration of the collections held by numerous institutions in the United States and Canada via the Reciprocal Research Network (RRN; see Rowley 2013), and (3) a systematic search of the collections databases of the Washington State University Museum of Anthropology (WSU MoA), which curates extensive collections from over 600 sites in the Pacific Northwest (Damitio et al. 2018; for details of search methodology, see Supplemental Text 1). Many of the references to pipes or pipe fragments had only very general provenience. However, only data on smoking artifacts with proveniences in well-documented archaeological contexts were included in the study. Site location and other data were compiled in a Microsoft Access database and exported to ArcGIS Desktop 10 for visualization and analysis.

\section{Chemical Analyses}

We employed chemical methods developed in part for this project that involve both basic biomarker screening and ancient residue metabolomics approaches. The biomarker approach employed here and by others (e.g., Echeverría et al. 2014; Eerkens et al. 2012; Rafferty 2002, 2006; Rafferty et al. 2012; Tushingham et al. 2013,2018 ) relies on the identification of a small number of compounds associated with specific plants. This approach can suggest the association of an artifact with a plant taxon, but further refinement is often impossible because target compounds are typically associated with more than one plant species or taxonomic group. Thus, while the biomarker nicotine indicates a likely association with tobacco, the biomarker approach cannot distinguish between species of Nicotiana.

Metabolomics is the study of the comprehensive complement of compounds involved in cellular metabolism. Every organism relies on many thousands of such compounds - metabolitesfor both basic and specialized biological 
functions. Most metabolites are shared across large taxonomic groupings, but some are unique in their presence or absence, or in their quantity within a species or genus (e.g., nicotine in the genus Nicotiana). A metabolomics approach in archaeological residue analysis seeks to reduce reliance on the presence of a single compound, as in the biomarker approach, and improve the possibility of species-level identification by instead comparing the entire metabolic "fingerprint" of the target species with the compounds extracted from an archaeological specimen. This fingerprint consists of the total metabolome-all of the metabolites in a biological sample-as characterized through chemical extraction and detection using a variety of instrumentation.

In this study, we characterized the chemical residue contents of archaeological artifacts and experimental specimens using methods developed and discussed in detail by Brownstein and colleagues (2020). For residue extraction, samples were submerged sequentially in three solvents-2\% aqueous tartaric acid, acetonitrile:2-propanol:water [3:2:2], and methyl tert-butyl ether - and sonicated for 10 minutes in each. We employed three solvents in sequence to extract the broadest possible range of compounds. Because the metabolomics analysis is untargeted, it is important that the compounds extracted and characterized be as nearly representative of the total metabolic fingerprint as possible in order to capture the uniqueness of each sample.

Following drying and resuspension in a smaller, more concentrated volume, extracts were analyzed using a liquid chromatography-mass spectrometry (LC-MS) system (see Brownstein et al. [2020] for details and technical specifications). The LC-MS data were processed using MZmine v2.32 (Pluskal et al. 2010). Among other things, this resulted in a list of all compounds in each analysis with the mass-to-charge ratio $(\mathrm{m} / \mathrm{z}$, which corresponds to the molecular mass of the detected compound), the retention time, and the peak intensity for each compound.

Before comparing the metabolic fingerprints of each sample, we conducted a targeted analysis of each specimen for known biomarkers. Although the vast majority of the compounds in the output of the LC-MS analysis are unidentified, it is possible to locate known compounds using chemical standards run under the same conditions. This was done for, among others, anabasine, cotinine, and nicotine as biomarkers for tobaccos and arbutin as a biomarker for $A$. uva-ursi. The tabular output of the LC-MS analysis was checked for these compounds in all specimens. Additionally, the presence or, more commonly, the absence of these compounds was confirmed through a direct visual analysis of the chromatograms and mass spectra produced by the LC-MS analysis.

For metabolomics analysis, the compounds extracted from each archaeological specimen were compared with the compounds present in pipes each experimentally smoked with one of 15 different plant species (Table 1) from a list compiled by Tushingham and colleagues (2018; see also Brownstein et al. 2020). This list encompasses plants known to have been used by Pacific Northwest peoples as well as a number of plants smoked elsewhere in precontact North America. These experimental samples were produced using commercially purchased unglazed ceramic pipes and plant samples either obtained from herbaria or grown by Brownstein under controlled conditions. Plant samples were dried, placed in the pipe bowl, and ignited. The smoke was then repeatedly drawn through the pipe and then expelled using a large syringe. Each experimentally smoked pipe was replicated five times, and each replicate was used to smoke five full bowls of the plant in question. For comparison to archaeological specimens, the replicates were combined.

To compare the contents of the residues extracted from archaeological specimens to the experimentally smoked plants, a Venn diagram method was used. The LC-MS output data were processed using Microsoft Excel to produce lists for each sample of the compounds present (represented by arbitrary unique numerical identifiers). This list for each archaeological specimen was compared to the compound lists for all experimentally smoked pipes and a blank control pipe using the Draw Venn Diagram web application (Van de Peer 2015). Of greatest relevance to our analysis are the categories where there are compounds shared uniquely between an 
Table 2. Radiocarbon Dates from Sites in the Mid-Columbia Study.

\begin{tabular}{|c|c|c|c|c|c|}
\hline $\begin{array}{l}\text { Site/Sample } \\
\text { Designation }\end{array}$ & Lab Number & $\begin{array}{c}\text { Conventional } \\
\text { Radiocarbon Date }\end{array}$ & $\begin{array}{c}2 \sigma \text { Calibrated } \\
\text { Date Range }(\mathrm{s})^{\mathrm{a}}\end{array}$ & $P$-Value ${ }^{\mathrm{b}}$ & Reference \\
\hline 45DO172-Feat6 & Beta- 185040 & $4030 \pm 40 \mathrm{BP}$ & $\begin{array}{l}\mathbf{4 4 1 7}-\mathbf{4 5 8 8} \text { cal BP } \\
4593-4613 \text { cal BP } \\
4766-4783 \text { cal BP }\end{array}$ & $\begin{array}{l}\mathbf{0 . 9 4 6} \\
0.025 \\
0.029\end{array}$ & Galm and Komen 2012 \\
\hline 45DO172-Feat10 & Beta-185041 & $4050 \pm 40 \mathrm{BP}$ & $\begin{array}{l}\mathbf{4 4 2 1}-\mathbf{4 6 2 9} \text { cal BP } \\
4762-4798 \text { cal BP }\end{array}$ & $\begin{array}{l}\mathbf{0 . 9 0 9} \\
0.078\end{array}$ & Galm and Komen 2012 \\
\hline 45GR27-224 & Beta-148984 & $800 \pm 60 \mathrm{BP}$ & $\begin{array}{l}\mathbf{6 5 7}-\mathbf{8 0 3} \text { cal BP } \\
810-829 \text { cal BP } \\
859-904 \text { cal BP }\end{array}$ & $\begin{array}{l}\mathbf{0 . 9 1 4} \\
0.021 \\
0.065\end{array}$ & Pouley 2001 \\
\hline 45GR27-196 & Beta-148982 & $1390 \pm 70 \mathrm{BP}$ & 1176-1416 cal BP & 0.983 & Pouley 2001 \\
\hline 45GR27-198 & Beta-148983 & $1520 \pm 40 \mathrm{BP}$ & 1334-1524 cal BP & 1.000 & Pouley 2001 \\
\hline 45GR30-1574 & D-AMS-019429 & $670 \pm 52 \mathrm{BP}$ & 549-687 cal BP & 1.000 & Damitio 2018 \\
\hline 45GR30-1988 & D-AMS-019430 & $884 \pm 66 \mathrm{BP}$ & 693-922 cal BP & 1.000 & Damitio 2018 \\
\hline
\end{tabular}

${ }^{a}$ Dates calibrated against the IntCal13 curve (Reimer et al. 2013) using CALIB rev. 5.0 (Stuiver et al. 2005).

${ }^{\mathrm{b}}$ Ranges where $p<0.01$ are omitted.

archaeological specimen and a single plant species. Where there are compounds shared only between a single plant species and a pipe specimen, there is evidence that the pipe was used to smoke that species. This association is strengthened by the presence of more than one shared compound between a plant and a pipe specimen, as do consistent matches across solvents (the extracts from each of the three solvents were treated as separate samples, meaning that each archaeological specimen or experimental pipe generated three analytical samples).

\section{Contamination}

The possibility of contamination is a major concern in the development and execution of ancient residue analyses (Washburn et al. 2014). The artifacts included in this study were collected in the mid-twentieth century, when tobacco use by researchers was more common, and little or no precautions would have been taken to avoid contamination either during initial collection and processing or in later collections work. Although strict precautions were taken during our lab work to avoid outside introduction of nicotine or other compounds, or crosscontamination between artifacts, we cannot say with absolute certainty that the nicotine and other compounds detected in this study were not introduced. With that disclaimer, however, we are confident that our results are not the result of contamination. First, all but one artifact (45GR30.2197, which was briefly on public display at a small museum) have been in closed repository storage since their collection except during rehousing and occasional examination by researchers in a few cases. Second, we do not see the consistent presence of any compound or group of compounds across any group of the artifacts analyzed that would suggest systematic exposure to a contaminant. In other words, we would be more concerned had we identified nicotine in many of the artifacts analyzed, instead of one.

\section{Mid-Columbia Pipe Study}

Thirty-four precontact pipes and pipe fragments from Interior Northwest archaeological sites are in collections at the WSU MoA. Of these, 12 pipes from three sites in the Mid-Columbia region were selected for biomarker and metabolomics analyses, all of which were collected from cache (45DO172), house floor (45GR27, 45GR30), and roasting feature (45GR27) contexts ranging in age from approximately 620 to 4500 cal BP (Table 2). Perhaps unsurprisingly, given the range of time covered, the study artifacts represent a diverse suite of styles and materials in use in the region (Figure 2). Materials include steatite $(n=8)$, basalt $(n=2)$, and finegrained sedimentary rock (i.e., siltstone; $n=2$ ). Styles include a thin tubular stem with a bell- 

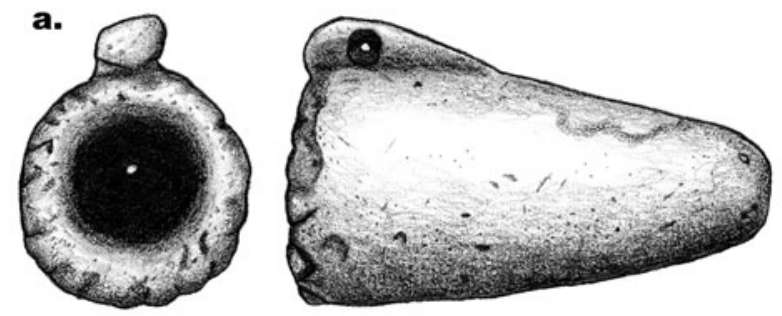

b.

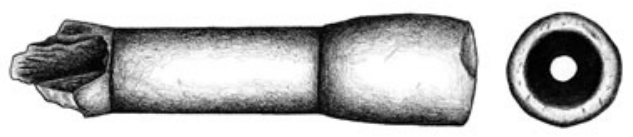

c.
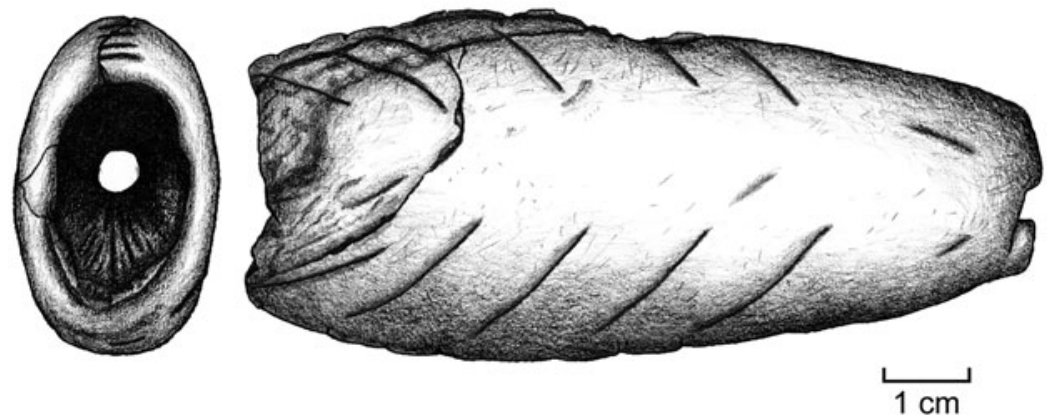

Figure 2. Selected pipes from the Mid-Columbia study representing the stylistic diversity of pipes in the region: (a) 45GR27.116, a conical granite pipe bowl; (b) 45GR30.2197, a fragment of a thin-walled tubular steatite pipe; and (c) 45D0172.2224, a robust oblong steatite pipe with regular incisions. Illustration by Trent Raymer.

shaped bowl and thickened mouthpiece $(n=6)$; a more robust conical bowl, likely used with a separate stem and mouthpiece $(n=2)$; the oblong pipes from the Cox's Pond site $(n=3)$; and the cigar-shaped specimen from Cox's Pond $(n=1)$.

45D0172. The Cox's Pond site (45DO172) in central Washington near the Columbia River consists of a variety of features, including hearths, house pits, and caches, and it was excavated in 1971 by the WSU Laboratory of Anthropology (Hartmann 1975). The four tested artifacts from this site are all complete pipes, and each was collected from different cache features dating to the earlier occupation that were set in or near house floors (Galm and Komen 2012). In each case, the pipes were stored along with burned stoned and bone tools, often with uniform orientation. In their reanalysis of the site, Galm and Komen (2012) argue that the caches, and in particular the pipes, are linked to the Western Idaho Archaic Burial Complex described by
Pavesic (1985). In support of this interpretation, Galm and Komen (2012) obtained two radiocarbon dates for 45DO172, giving the artifacts from this site an age of about $4500 \mathrm{cal} \mathrm{BP}$ (Table 2).

The 45DO172 pipes represent two rare pipe forms in the region. Three pipes (45DO172.2221, 2222 , and 2224) are roughly ovate in shape and relatively flat, with an elliptical transverse cross section (Figure 2c). A roughly contemporaneous pipe from a lower Snake River site resembling these artifacts tested positive for nicotine (Tushingham et al. 2018). A fourth pipe from 45DO172 (45DO172.2223) has an unusual, elongated cigar-shaped form, which is round in cross section and tapers at one end, likely forming the mouth of the pipe.

45GR27. The Ridge Bottom Village site (45GR27) is located near 45GR30 (see below) along the shore of Moses Lake in central Washington state. The site consists of 33 generally circular depressions, likely house pits, three of 
which were excavated (Daugherty 1952). Two pipe artifacts were collected from the site, and both were selected for analysis: a complete pipe bowl (45GR27.116) found in association with Feature 1, identified by Pouley (2001) as a roasting pit, and a pipe fragment (45GR27.74) found in the floor of House Pit 1. The complete granite bowl is conical and thick walled, and it was likely used in conjunction with an inset stem made of some perishable material. The pipe fragment is similarly robust in construction and material, suggesting it was similar in style to the recovered bowl (Daugherty 1952:381), even though these artifacts were recovered from contexts dating several hundred years apart. The roasting pit associated with the complete pipe bowl dates to $1520 \pm 40$ BP (1334-1524 cal BP; Table 3; Pouley 2001). House Pit 1 , the context for the pipe fragment, has not been radiocarbon dated, but Pouley (2001:83-84) suggests that it is roughly contemporaneous with the adjacent House Pit 2 , which dates to $800 \pm 60 \mathrm{BP}(657-803 \mathrm{cal} \mathrm{BP})$.

45GR30. Long Beach Village (45GR30) excavations were part of the 45GR27 project by Daugherty (1952). A total of 11 pipe fragments were collected from the floor of the single excavated house pit. All were recovered at similar depths, but their distribution did not reveal any apparent distribution or pattern. Notably, all 11 pipe fragments collected at 45GR30 are distinctly different from those from nearby 45GR27. Where the complete pipe and fragment from the latter site are robust and conical in form, the fragments from the former are delicate and made of steatite, likely representing pieces of tubular pipes. Most of the 45GR30 specimens are small, averaging a maximum length of 2.22 $\mathrm{cm}$. The most complete specimen from 45GR30 (45GR30.2197, Figure 2b) suggests the form of the pipes from which the other fragments originated: tubular with a bell-shaped bowl and flared mouthpiece.

Six of the 11 pipe fragments from 45GR30 were included in the study. Those exhibiting charring on their interior surface and/or other characteristics suggesting that they were a bowl or mouthpiece fragment (e.g., grinding on one surface) were preferred candidates for residue analysis.

Radiometric dating of materials from 45GR30 indicates that the site (and associated pipes) dates
Table 3. Summary of Results by Site.

\begin{tabular}{|c|c|c|}
\hline Region \& Site & Nicotine & Arbutin \\
\hline \multicolumn{3}{|l|}{ Fraser Valley } \\
\hline DjRi-5 & - & - \\
\hline DgRr-6 & - & - \\
\hline Boundary Bay Site & - & - \\
\hline \multicolumn{3}{|l|}{ North Cascades } \\
\hline 45PI43 & - & - \\
\hline \multicolumn{3}{|l|}{ Mid-Columbia } \\
\hline 45GR27 & + & - \\
\hline 45GR30 & - & - \\
\hline 45DO172 & - & - \\
\hline \multicolumn{3}{|l|}{ Lower Columbia ${ }^{\mathrm{a}}$} \\
\hline $45 \mathrm{AS} 87^{\mathrm{b}}$ & + & - \\
\hline 45GA7 & + & - \\
\hline 45GA61 & + & - \\
\hline 45WW6 & + & - \\
\hline \multicolumn{3}{|c|}{ Southern Northwest Coast ${ }^{\mathrm{c}}$} \\
\hline CA-DNO-26 & + & - \\
\hline CA-DNO-333 & + & - \\
\hline
\end{tabular}

${ }^{\mathrm{a}}$ See Tushingham et al. 2018.

${ }^{\mathrm{b}}$ Postcontact context.

${ }^{\mathrm{c}}$ See Tushingham et al. 2013.

to the Late Archaic period (2000-230 BP, as defined by Andrefsky [2004]). This date is supported by two charcoal samples, both recovered from charred areas in the occupation floor and identified as species of Artemisia (sagebrush). A younger date $(670 \pm 52 \mathrm{BP} ; 549-687 \mathrm{cal} \mathrm{BP})$ is closely associated with artifact 45GR30.118, whereas an older dating sample $(884 \pm 66 \mathrm{BP}$; 693-922 cal BP) was collected from a large, diffuse charred area in the main house pit that also yielded three of the 11 pipe fragments collected at the site.

\section{Fraser Valley Pipe Study}

Thirty-five pipes, pipe fragments, and pipe blanks from Esilao (DjRi-5), a pithouse village in the Fraser Canyon dating from $5490 \pm 500$ $\mathrm{BP}$ to the early nineteenth century AD (Borden 1965; Mitchell 1963), were included in the study. Tested pipe artifacts from DjRi-5-a subset of a total of 62 such artifacts collected from House Pit 1-include a variety of forms constructed primarily of ground and carved steatite. The majority are similar to tubular forms common in the Mid-Columbia study, but they have comparatively thicker walls (for a detailed discussion of stylistic variation of site pipes, see Mitchell [1963]). Chronology at the site is 
difficult to parse from published materials, but most pipes from Esilao also appear to date from the Late Archaic, whereas some are associated with postcontact deposits. One siltstone pipe from the Marpole (2400-ca. 1300 BP; Moss 2011:98) component of the Glenrose Cannery site (DgRr-6) on the Fraser River nearer the coast (Matson 1976:154) was tested in addition to those from DjRi-5.

\section{Other Studies}

Pipes found in relative isolation were also tested: a pumice pipe bowl from Fryingpan Rockshelter (45PI43) on the eastern slopes of Mt. Rainier and a carved steatite pipe recovered during construction at a residence in Pasco, Washington, in 2017. Lubinski and Burtchard (2005) assign a range of 250-1150 cal BP to the human use of 45PI43. The pipe, however, was collected from a cache in the wall of the rockshelter (Rice 1965) and cannot be confidently associated with any particular date or period. The pipe from Pasco, Washington, is difficult to contextualize, although its material and intricate decorative carving suggest a link to the Late Archaic (e.g., Duff 1956). This latter pipe was collected and stored for some time by a nonprofessional, and it may have been exposed to greater risk of contamination.

\section{Results}

\section{Artifact Distribution}

At least 62 archaeological collections from the Pacific Northwest contain stone pipe artifacts from well-provenienced contexts (Figure 3). This includes several dozen pipes or pipe fragments from 36 sites discovered through the literature and the Reciprocal Research Network survey, as well as 56 pipe artifacts from 26 sites documented in WSU MoA collections. Figure 3 illustrates the spatial distribution of these artifacts, indicating a regional pattern of distribution wherein stone pipes are rare west of the Cascade Range and largely limited to the Columbia and Fraser Plateaus, as well as along the Pacific Coast south of the Columbia River. Most of the pipe artifacts in the region lack fine-grained chronological associations. However, the majority are from throughout the Late
Archaic (2000 BP-230 BP), with the Cox's Pond artifacts serving as older outliers. Although additional specimens may be discovered and added to this database in the future, this is currently the most comprehensive compilation of pipes from the region and therefore the best spatiotemporal snapshot of precontact pipe-smoking practices we have at present.

\section{Chemical Residue Analysis}

All 49 artifacts from the studies presented here tested negative for the presence of arbutin, the compound associated with A. uva-ursi, and all but one sample tested negative for the presence of nicotine, which is associated with Nicotiana species (Table 3). A pipe bowl from 45GR27 tested positive for the presence of nicotine, and metabolomics results indicate an association with $N$. quadrivalvis and additional smoke plants, particularly Rhus glabra (smooth sumac; see Supplemental Table 1).

\section{Mid-Columbia Pipe Study}

Ancient residue metabolomics analyses of the 12 specimens from the three Mid-Columbia sites provided insights beyond presence/absence biomarker analyses. The results of these analyses show evidence for the species of tobacco in use as well as for the use of smoke plants other than tobacco. One artifact-45GR27.116, a basalt pipe bowl from near Moses Lake, Washington (Figure 2a) - was found to have contained nicotine. This artifact also contained the most interesting metabolomic fingerprint, showing more shared compounds across more species than any other specimen in the study (Table 4). 45GR27.116 was shown to also be associated with species including A. uva-ursi, Verbascum thapsus, and, most strongly, Rhus glabra. Of the compounds extracted from that artifact, 12 were shared with those extracted from a pipe experimentally smoked with $R$. glabra. A more focused analysis of this artifact by Brownstein and colleagues (2020) supports and strengthens this association, and it further demonstrates that $N$. quadrivalvis is the most likely tobacco species smoked using this bowl. V. thapsus was shown to have a similarly strong association in this analysis, but it is a non-native species that arrived in the region no later than the late eighteenth 


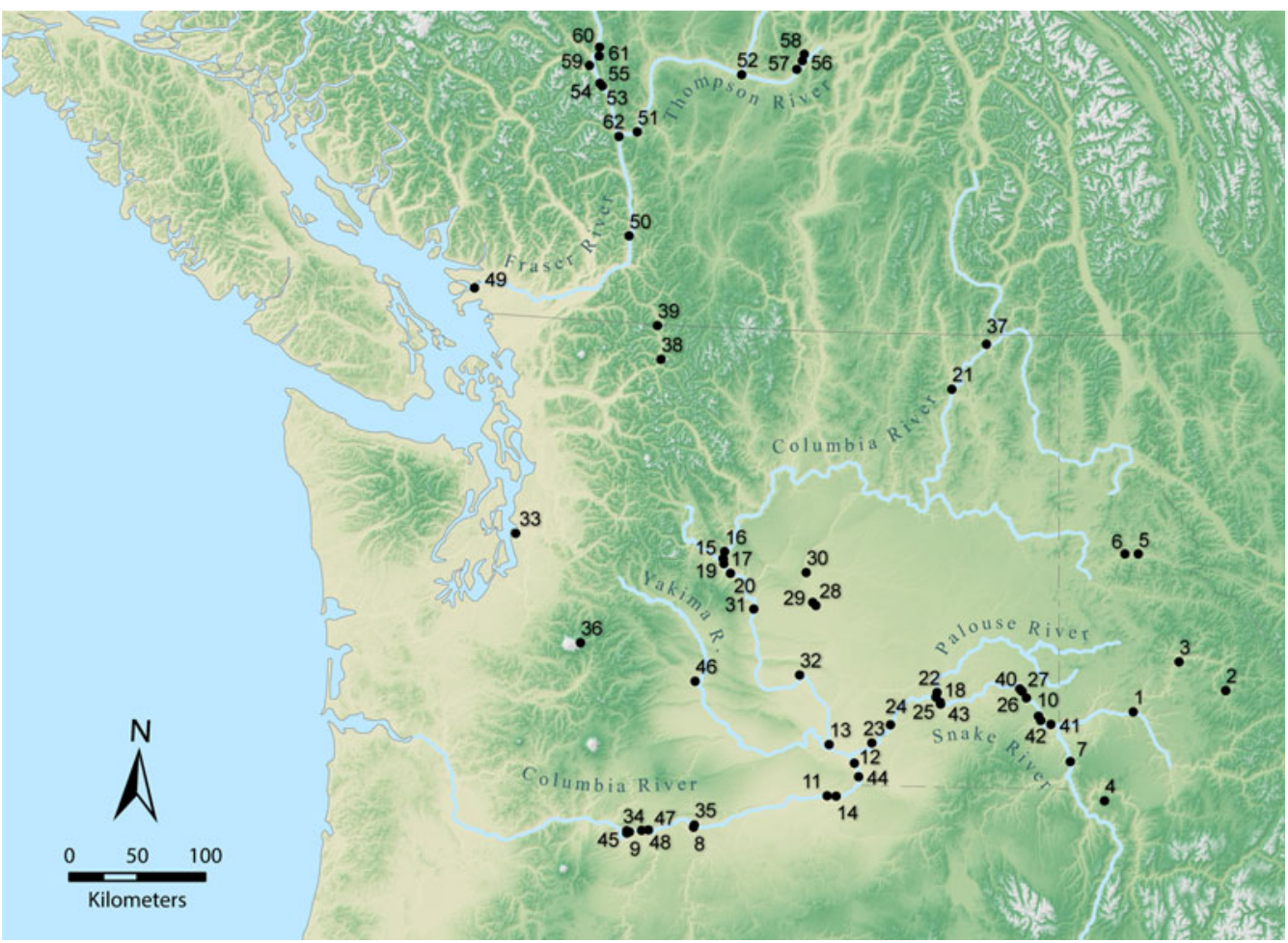

Figure 3. This map shows archaeological sites throughout the Pacific Northwest where pipes or pipe fragments have been identified. See Supplemental Text 2 for a key to sites and references. (Color online)

Table 4. Results of Metabolomics Analysis for 45GR27.116-A Nicotine-Positive Pipe.

\begin{tabular}{lccc}
\hline Species & Compounds Shared & $\begin{array}{c}\text { No. of Unique Compounds } \\
\text { Attributed to Species }\end{array}$ & Percent Shared \\
\hline Artemisia ludoviciana & 4 & 607 & 0.7 \\
Arctostaphylos uva-ursi & 2 & 363 & 0.6 \\
Cornus sericea & 4 & 219 & 1.8 \\
Gaultheria shallon & 4 & 594 & 0.7 \\
Lobelia inflata & 3 & 448 & 0.7 \\
Nicotiana attenuata & 0 & 307 & 0.0 \\
Nicotiana glauca & 2 & 320 & 0.6 \\
Nicotiana obtusifolia & 0 & 261 & 0.0 \\
Nicotiana quadrivalvis & 2 & 462 & 0.4 \\
Nicotiana rustica & 3 & 372 & 0.8 \\
Nicotiana tabacum & 0 & 221 & 0.0 \\
Rhus glabra & 12 & 740 & 1.6 \\
Salvia sonomensis & 3 & 923 & 0.3 \\
Taxus brevifolia & 3 & 705 & 0.4 \\
Verbascum thapsus & 11 & 878 & 1.3 \\
\hline
\end{tabular}

century, and it could not have been smoked using 45GR27.116. It is possible that a related or metabolically similar plant was smoked. These results show unambiguously that nontobacco plants were smoked alone or in mixtures in this region in the past.

While the rest of the specimens in this study show numbers of shared compounds low enough 
to attribute to noise, it may be worth noting that all of the 12 tested pipes shared two compounds uniquely associated with $N$. quadrivalvis and either one or two compounds associated with $T$. brevifolia. These results are not conclusive evidence for the consistent use of these two species in the region, but they are consistent with our expectations based on the ethnohistoric record. Additional analyses of pipes in the future from the area will increase our confidence in this interpretation.

\section{Fraser Valley Pipe Study}

None of the 35 tested artifacts from DjRi-5 and DgRr-6 contained biomarkers for tobacco or $A$. uva-ursi metabolomics analysis of the specimens, however, revealed some compelling patterns (Supplemental Table 1). Artifacts DgRr-6_1343 and DjRi-5_5244 shared the most metabolites with pipes smoked with Salvia sonomensis, whereas DjRi-5_8317 shared the most metabolites with Cornus sericea. The present distribution of $S$. sonomensis is restricted to California (USDA, NRCS 2021), indicating that another Salvia species may have been smoked. No patterns of shared metabolites were observed in the other artifacts.

\section{Other Studies}

The pumice pipe collected at 45PI43 did not contain biomarkers for tobacco or A. uva-ursi. Metabolomics analysis of the artifact did not indicate a strong association with any plant taxon, although extracts from the pipe did contain single compounds shared with A. ludoviciana, L. inflata, and N. tabacum.

The results of metabolomics analysis of the residues extracted from the Pasco pipe are also inconclusive. There was no detection of nicotine or other known biomarkers, but the residues from the pipe share compounds with every species in our analysis, including each tobacco species and commercially available tobacco. We interpret this unique prevalence of matches across unrelated species as evidence of contamination either through taphonomic processes or during handling following collection.

\section{Discussion}

Pipes have been used in the Americas to ingest mind-altering plants for thousands of years.
The pipes discussed in this article range in age from the mid-Holocene-pipes from the Cox's Pond site dating to approximately $4500 \mathrm{cal} \mathrm{BP}$ are the oldest in the region and among the oldest in the Americas - to the end of the precontact era. Nearly all of the pipes from the region were collected from Plateau sites on major rivers, many thousands of miles from the geographic origin of domesticated tobaccos. The detection of nicotine in 45GR27.116 is the northernmost evidence of tobacco use in ancient North America as well as the oldest chemical evidence of tobacco use in the West. Charred Nicotiana sp. seeds from a Paleoindian site in Utah predate this evidence by several thousand years at approximately 12,300 cal BP (Duke et al. 2019). Carmody, Davis, and colleagues (2018) demonstrate tobacco use in southeastern North America at 3635-3480 cal BP, suggesting distinct timelines for the spread of tobacco species extant in the east ( $N$. tabacum, $N$. rustica) and those in the west ( $N$. attenuata, $N$. quadrivalvis, N. glauca).

In the Inland Pacific Northwest, pipes are commonly perceived to be found almost exclusively in burial contexts. The fact that many of the pipes found as grave goods were constructed of steatite-an uncommon, soft stone desirable for the ease with which it may be carved (Duff 1956) — has led to pipes being interpreted as a prestige good or wealth indicator that would have been possessed largely by elites (Hayden and Schulting 1997). Although it is true that pipes are a common feature of burial assemblages (Schulting 1995), our study shows that pipes and pipe fragments have been collected from a variety of archaeological contexts, including house floors, hearth features, and caches. Furthermore, pipes were also frequently constructed from materials including basalt and medium to fine-grained sedimentary rocks, not just fine-grained steatite, which would have been an exotic resource imported to areas distant from quarries. Such evidence suggests a broader role for pipes than as an indicator of status. Pipe smoking may have been more common than previously thought, with uses in various spheres of life.

Although the biomarker nicotine has been rare, and arbutin nonexistent (Table 3), the 
nicotine-positive result from 45GR27 in central Washington state is significant. First, this represents the northernmost identification of nicotine in a precontact pipe anywhere in the Americas. Second, with a date of 1334-1524 cal BP, this is the oldest pipe in western North America to be chemically associated with tobacco use, demonstrating the deep-time continuity of a practice that the Indigenous peoples of this region continue to this day. Metabolomics analyses show that the tobacco used was likely N. quadrivalvis (Brownstein et al. 2020), indicating use of an ethnographically preferred species (Douglas 1914; Kroeber 1941; Setchell 1921; see also Turner and Taylor 1972) as well as ancient plant management and cultivation practices, given that $N$. quadrivalvis is very rare outside of cultivation so far north.

Situating the two larger studies considered in this article in the context of previous research in this area, we begin to get a sense of the northern limits of past tobacco use. The Fraser Valley study suggests that tobacco was not in use in the distant past on the western edge of the Inland Plateau, at least at DjRi-5. Furthermore, although we have found one positive datum supporting tobacco use in the past in the Mid-Columbia region, it rests among many negatives. Whereas in the Mid-Columbia study presented here 12 artifacts from three sites yielded only one nicotine-positive result, Tushingham and colleagues (2018) found nicotine in seven of 11 tested precontact smoking artifacts from the southern Columbia Plateau. This incongruity suggests to us that the positive result from 45GR27 was an outlier: tobacco use was less common in the past the further northwest one goes from the Lower Columbia and Upper Snake Rivers.

This trend is illustrated in Figure 4, which summarizes the results of all previous ancient residue testing for nicotine throughout the Pacific Northwest, as well as at three sites in central coastal California from which dental calculus was tested (Eerkens et al. 2018). It is clear from studies published in the past decade or so that tobacco use was largely limited to the southern Inland Pacific Northwest. Significant gaps remain, however, in the geographical coverage of testing for the occurrence of nicotine and other compounds in ancient contexts in the region, particularly when compared with the distribution of stone smoking pipes found in archaeological contexts (Figure 3 ).

Smoking residues have only been tested from one site (Keatley Creek; Hayden 2000) in the Inland Plateau of British Columbia. Further studies should be undertaken that cover more sites in the region. Additionally, this and other studies have largely failed to address the possibility of ancient tobacco or other smoking in the Northwest Coast and Plateau in Oregon. Kroeber (1941) and others (see Phillips 2016) indicate an Indigenous tradition of tobacco cultivation along the Oregon coast nearly to the mouth of the Columbia River (Figure 1). This-in conjunction with an archaeological record clearly indicating past smoking (Endzweig 1989; Nelson 2000; Phillips 2016) — suggests that the picture remains incomplete. It is also important to bear in mind that smoking is not the only way that the peoples of this region consumed intoxicating plants. Tobacco is an important plant to the Haida and Tlingit of the northern coast, but it may be archaeologically invisible because it was chewed rather than smoked (Turner and Taylor 1972).

Our results have also provided insights into the utilization of plants other than tobacco. There is evidence from DjRi-5 that Cornus sericea and some species of Salvia were smoked in the past. The latter may perhaps be $S$. dorrii, which is native to the Plateau region and is known to have been utilized by Plateau peoples in nonsmoking medicinal practices (Moerman 1998:510). C. sericea, on the other hand, is known to have been used for smoking in the postcontact era. Compounds associated with $R$. glabra were found the in the extracts from the nicotine-positive pipe from 45GR27 and in smaller numbers in other pipes. $R$. glabra was used medicinally (but not smoked) by a number of Plateau peoples (Moerman 1998:471-472) and was smoked "like tobacco" by at least one group - the Northern Secwepemc of the Fraser Plateau to the north (Parish et al. 1999:70). One Secwepemc elder, Lilly Harry of Dog Creek, commonly referred to the plant as "Indian tobacco" (Ignace and Ignace 2017:49, 508). We interpret the presence of compounds associated with this species in pipes from the middle 


\section{Sites}

1. Keatley Creek (EeRI-17)

2. Esilao (DjRi-5)

3. Glenrose Cannery (DgRr6)

4. Cox's Pond (45DO172)

5. Fryingpan Rockshelter (45PI43)

6. Long Beach Village (45GR30)

7. Ridge Bottom Village (45GR27)

8. Wexpusnime (45GA61)

9. Offield Bar (45GA7)

10. Pasco

11. Fort Walla Walla/Nez Perce (45WW6)

12. CA-DNO-26

13. CA-DNO-333

14. CA-ALA- 554

15. CA-SCL-928

16. CA-SCL-919

Nicotine-positive sites bolded
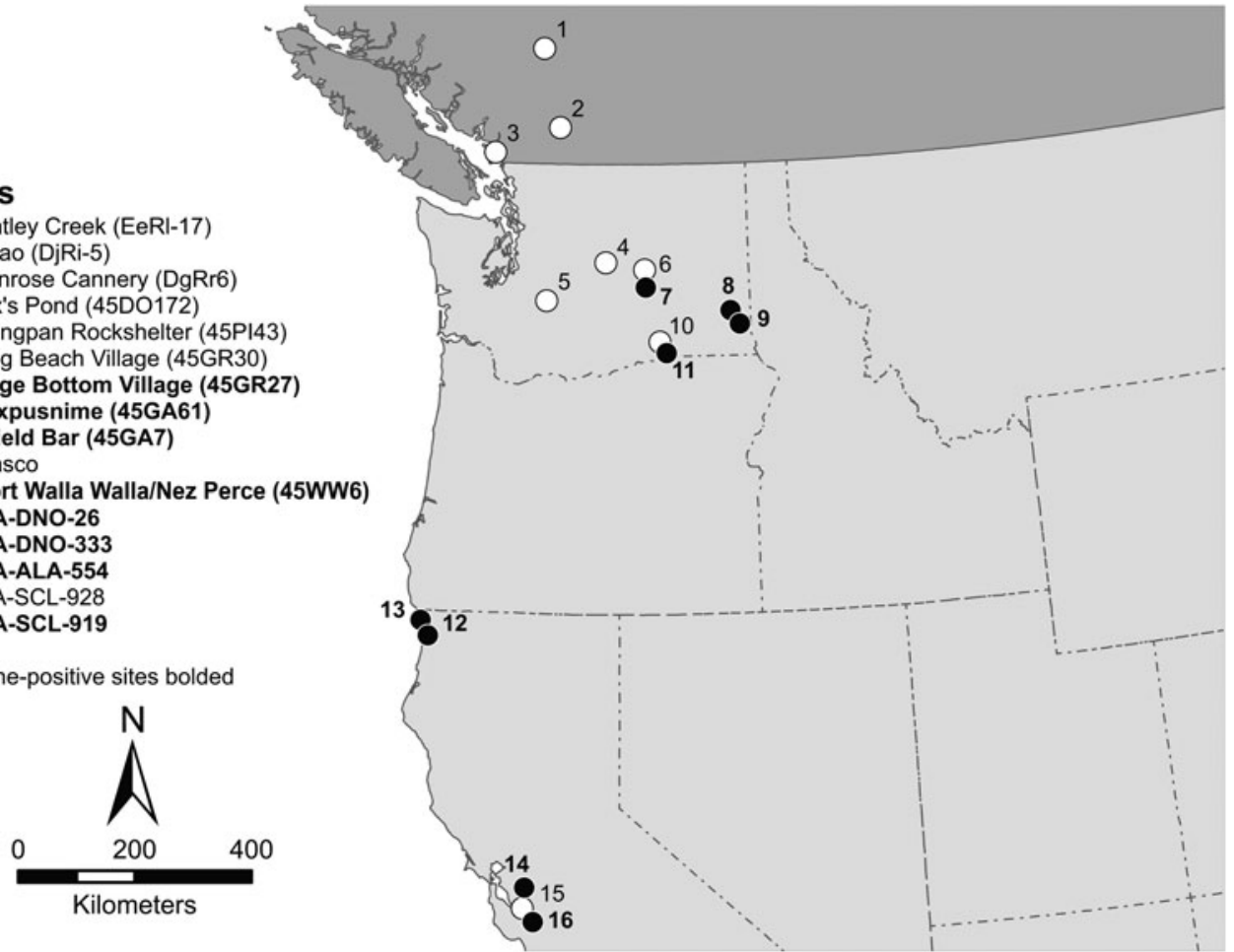

Figure 4. This map shows all sites from which pipes were tested for nicotine. Black circles indicate sites where a specimen contained nicotine.

Columbia as a smoking practice that perhaps did not persist from the past through to the contact era. This is intriguing considering that $R$. glabra was used in other ways by peoples of the central Plateau at the time of European contact.

The use of metabolomics analysis in this kind of archaeological study is new, and we are beginning to explore its potential (Brownstein et al. 2020). In the studies presented here, metabolomics analyses have allowed us to detect compounds in artifacts associated with species that would otherwise have been invisible to us archaeologically.

\section{Summary and Conclusion}

The archaeological record of stone smoking pipes in the Inland and southern Coastal Pacific Northwest alone confirms the deep antiquity of smoking in the region, and it is among the earliest and longest records of ancient smoking pipes anywhere in the Americas. This study has considered the spatiotemporal distribution of this artifact type and broader implications for understanding smoking in the past. Drawing on an ethnohistoric record indicating that many plants were traditionally smoked in this region, we have sought to explore through residue analyses of stone smoking pipes presented here and elsewhere (Brownstein et al. 2020; Tushingham et al. 2013, 2018) how long these plants have been used for this purpose.

We focused on tobaccos (N. attenuata and $N$. quadrivalvis) and kinnikinnick (A. uva-ursi) by testing for biomarkers known to be associated with these species, given that they are among the most frequently referenced smoke plants. We found that the oldest artifact to test positive for nicotine in the region was from the Ridge Bottom Village site (45GR27) in central Washington state, and it was associated with a radiocarbon date of 1334-1524 cal BP. This site is also the northernmost in the region to be positively associated with tobacco use in the 
precontact era. Our findings superficially contradict ethnographic data showing traditional tobacco use in the northern Plateau among the Nlaka'pamux (Thompson), Secwepemc, Kutenai, and others (Teit 1900, 1909; Turner 2014; Turner and Taylor 1972). However, our samples are limited chronologically and spatially. Tobacco smoking among these peoples may have appeared later in the precontact or early contact eras after the deposition of the artifacts tested in our studies. Cultural practices are never static, after all. Alternatively, spatial lacunae in our testing (in Secwepemcor Nlaka'pamux areas, for example) may mean that we are simply missing evidence of ancient tobacco use in the northern Plateau.

None of the specimens tested were associated with A. uva-ursi. Although our evidence does not indicate that A. uva-ursi was smoked, paleoethnobotanical studies have shown that the plant was in use in both inland British Columbia (Lepofsky and Lyons 2013; Lyons et al. 2018) and the Columbia Plateau (e.g., Carney 2018). Our synthesis of residue studies suggests that the Middle Columbia area may constitute the northern limits of tobacco use in the Late Archaic. Very low positive rates for tobacco use in that area contrast with frequent positive results for nicotine on the Lower Columbia and Upper Snake Rivers (see Tushingham et al. 2018).

Future work should expand the geographic distribution of tested artifacts, focusing on the northern Columbia Plateau, inland British Columbia, and the Oregon coast. Archaeological smoking pipes evince that smoking has been an important part of Indigenous lifeways for thousands of years, and we attempt in this study to contribute to a growing understanding of the spatial and temporal limits of these practices in the Northwest and throughout the Americas.

Acknowledgments. The authors thank the Confederated Tribes of the Colville Reservation for their support and permissions to work with the artifacts analyzed in the MidColumbia study. We thank the Nez Perce Tribe of Idaho for its support and permissions in previously published studies also discussed here. We also thank the U.S. Bureau of Reclamation, the Washington State Department of Transportation, and the Walla Walla District of the US Army Corps of Engineers for their permissions. For their permissions to analyze artifacts in the Fraser Valley study, we thank Kwantlen
First Nation and the Yale First Nation. We also thank the Musqueam Indian Band and the Sto:lo Nation. We also thank Patricia Ormerod of the University of British Columbia Laboratory of Anthropology for her invaluable efforts enabling us to conduct the portions of this research that took place there. This material is based in part on work supported by the National Science Foundation under grants No. 1419506 and No. 1918966.

Data Availability Statement. Microsoft Excel spreadsheets containing the unprocessed results of LC-MS analyses are available from the authors upon request.

Supplemental Materials. For supplemental materials accompanying this article, visit https://doi.org/10.1017/aaq. 2021.39 .

Supplemental Text 1. Explication of Pipe Artifact Search Methods.

Supplemental Text 2. Key to Figure 3 with References.

Supplemental Table 1. Detailed Results of Mid-Columbia and Fraser Valley Residue Analyses.

\section{References Cited}

Andrefsky, William

2004 Materials and Contexts for a Culture History of the Columbia Plateau. In Complex Hunter-Gatherers: Evolution and Organization of Prehistoric Communities on the Plateau of Northwestern North America, edited by William C. Prentiss and Ian Kuijt, pp. 23-35. University of Utah Press, Salt Lake City.

Borden, Charles E.

1965 Radiocarbon and Geological Dating of the Lower Fraser Canyon Archaeological Sequence. In Radiocarbon and Tritium Dating, edited by Rainer Berger and Leona Marshall Libby, pp. 165-178. United States Atomic Energy Commission, Oak Ridge, Tennessee.

Brownstein, Korey J., Shannon Tushingham, William J. Damitio, Tung Nguyen, and David R. Gang

2020 An Ancient Residue Metabolomics-Based Method to Distinguish Use of Closely Related Plant Species in Ancient Pipes. Frontiers in Molecular Biosciences 7 (133). DOI:10.3389/fmolb.2020.00133.

Carmody, Stephen, Jera Davis, Surendar Tadi, Joshua S. Sharp, Ryan K. Hunt, and Jon Russ

2018 Evidence of Tobacco from a Late Archaic Smoking Tube Recovered from the Flint River Site in Southeastern North America. Journal of Archaeological Science: Reports 21:904-910. DOI:10.1016/j.jasrep.2018. 05.013 .

Carmody, Stephen B., Megan C. Kassabaum, Ryan K. Hunt, Natalie Prodanovich, Hope Elliott, and Jon Russ

2018 Residue Analysis of Smoking Pipe Fragments from the Feltus Archaeological Site, Southeastern North America. Journal of Archaeological Science: Reports 17:640-649. DOI:10.1016/j.jasrep.2017.12.011.

Carney, Molly

2018 Macrobotanical Analysis of Archived Earth Oven Soil Samples (45PO422), Kalispel Fish Hatchery. Report submitted to the Kalispel Natural Resources Department, Usk, Washington.

Carod-Artal, Francisco Javier

2015 Hallucinogenic Drugs in Pre-Columbian 
Mesoamerican Cultures. Neurología (English Edition) $30: 42-49$

Damitio, William J.

2018 Pipes and Smoking in Precontact Northwest Societies. Master's thesis, Department of Anthropology, Washington State University, Pullman.

Damitio, William J., Andrew Gilreath-Brown, and Shannon Tushingham

2018 Seeing the Forest for the Trees: A Spatial Database to Enhance Potential of Legacy Collections at the Washington State University Museum of Anthropology. Journal of Northwest Anthropology 52:183-199.

Daugherty, Richard D.

1952 Archaeological Investigations in O'Sullivan Reservoir, Grant County, Washington. American Antiquity 17:374-383.

Douglas, David

1914 Journal Kept by David Douglas during His Travels in North America 1823-1827. William Wesley \& Son, London.

Duff, Wilson

1956 Prehistoric Stone Sculpture of the Fraser River and Gulf of Georgia. Anthropology in British Columbia. British Columbia Provincial Museum, Victoria, British Columbia.

Duke, Daron, Sarah K. Rice, and D. Craig Young

2019 The Playas Archaeological Inventory: 6,914 Acres on the Utah Test and Training Range including Portions of the West Distal Delta of the Old River Bed and Test Excavations at the Wishbone Site (42TO6384), Tooele County, Utah. Report prepared for the Center for Integrated Research on the Environment, University of Montana, and Hill Air Force Base. Far Western Anthropological Research Group, Henderson, Nevada.

Echeverría, Javier and Hermann M. Niemeyer

2013 Nicotine in the Hair of Mummies from San Pedro de Atacama (Northern Chile). Journal of Archaeological Science 40:3561-3568. DOI:10.1016/j.jas.2013.04.030.

Echeverría, Javier, María Teresa Planella, and Hermann M. Niemeyer

2014 Nicotine in Residues of Smoking Pipes and Other Artifacts of the Smoking Complex from an Early Ceramic Period Archaeological Site in Central Chile. Journal of Archaeological Science 44:55-60. DOI:10.1016/ j.jas.2014.01.016.

Eerkens, Jelmer, Dominique Ardura, Oliver Fiehn, Jennifer Blake, Kari Lentz, Shannon Tushingham, and Mine Palazoglu

2012 GC-MS Analysis of Residues Reveals Nicotine in Two Late Prehistoric Pipes from CA-ALA-554. Proceedings of the Society for California Archaeology 26:212-219.

Eerkens, Jelmer W., Shannon Tushingham, Korey J. Brownstein, Ramona Garibay, Katherine Perez, Engel Murga, Phil Kaijankoski, Jeffrey S. Rosenthal, and David R. Gang

2018 Dental Calculus as a Source of Ancient Alkaloids: Detection of Nicotine by LC-MS in Calculus Samples from the Americas. Journal of Archaeological Science: Reports 18:509-515. DOI:10.1016/j.jasrep.2018.02.004.

Einöther, Suzanne J. L., and Timo Giesbrecht

2013 Caffeine as an Attention Enhancer: Reviewing Existing Assumptions. Psychopharmacology 225:251274. DOI:10.1007/s00213-012-2917-4.

Endzweig, Paula

1989 Of Pots, Pipes, and People: Prehistoric Ceramics of
Oregon. In Contributions to the Archaeology of Oregon 1987-1988, edited by Rick Minor, pp. 157-177. Association of Oregon Archaeologists Occasional Papers No. 4. Association of Oregon Archaeologists, Portland. Furst, Peter T.

1972 Flesh of the Gods: The Ritual Use of Hallucinogens. Praeger, New York.

Galm, Jerry R., and Dana Komen

2012 Cox's Pond and Middle Holocene Ceremonial Activity in the Inland Pacific Northwest. In Festschrift in Honor of Max G. Pavesic, edited by Kenneth C. Reid and Jerry R. Galm, pp. 73-96. Journal of Northwest Anthropology, Memoir 7. Northwest Anthropology, Richland, Washington.

Goodspeed, Thomas Harper

1954 The Genus Nicotiana: Origins, Relationships and Evolution of Its Species in the Light of Their Distribution, Morphology, and Cytogenetics. Chronica Botanica, Waltham, Massachusetts.

Gunther, Erna

1973 Ethnobotany of Western Washington: The Use and Knowledge of Indigenous Plants by Native Americans. Rev. ed. University of Washington Press, Seattle.

Hagen, Edward H., Melissa J. Garfield, and Roger J. Sullivan

2016 The Low Prevalence of Female Smoking in the Developing World: Gender Inequality or Maternal Adaptations for Fetal Protection? Evolution, Medicine, and Public Health 2016(1):195-211. DOI:10.1093/ emph/eow013.

Hagen, Edward H., Casey J. Roulette, and Roger J. Sullivan

2013 Explaining Human Recreational Use of "Pesticides": The Neurotoxin Regulation Model of Substance Use vs. the Hijack Model and Implications for Age and Sex Differences in Drug Consumption. Frontiers in Psychiatry 4:142.

Hagen, Edward H., Roger J. Sullivan, Robert Schmidt, Genela Morris, Richard Kempter, and Peter Hammerstein

2009 Ecology and Neurobiology of Toxin Avoidance and the Paradox of Drug Reward. Neuroscience 160(1):69-84.

Hagen, Edward H., and Shannon Tushingham

2019 The Prehistory of Psychoactive Drug Use. In Handbook of Cognitive Archaeology, edited by Tracy B. Henley, Matt J. Rossano, and Edward P. Kardas, pp. 471498. Routledge, New York.

Hammet, Julia E.

2000 Out of California: Cultural Geography of Western North American Tobacco. In Tobacco Use by Native North Americans: Sacred Smoke and Silent Killer, edited by Joseph C. Winter, pp. 128-140. University of Oklahoma Press, Norman.

Hartmann, Glenn D.

1975 The Archaeology of the Cox's Pond Site, 45DO172. Project Report No. 17. Laboratory of Anthropology, Washington State University, Pullman.

Hayden, Brian

2000 Prestige Artifacts at Keatley Creek. In The Ancient Past of Keatley Creek: II: Socioeconomy, edited by Brian Hayden, pp. 189-202. Archaeology Press, Simon Fraser University, Burnaby, British Columbia.

Hayden, Brian, and Rick Schulting

1997 The Plateau Interaction Sphere and Late Prehistoric Cultural Complexity. American Antiquity 62:51-85. DOI: $10.2307 / 282379$.

Ignace, Marianne, and Ronald Eric Ignace

2017 Secwépemc People, Land, and Laws. McGillQueen's Press, Montreal. 
Keddie, Grant

2016 Aboriginal Use and Context of Pipes, Tobacco, and Smoking in Northwestern North America. In Perspectives on the Archaeology of Pipes, Tobacco and other Smoke Plants in the Ancient Americas, edited by Elizabeth Anne Bollwerk and Shannon Tushingham, pp. 157-181. Springer, Cham, Switzerland.

Kroeber, Alfred L.

1941 Culture Element Distributions: XV: Salt, Dogs, Tobacco. Anthropological Records 6(1):1-20.

Lepofsky, Dana, and Natasha Lyons

2013 The Secret Past Life of Plants: Paleoethnobotany in British Columbia. BC Studies: The British Columbian Quarterly 179:39-83.

Loughmiller-Cardinal, Jennifer

2018 Mayan Ritual Beverage Production: Considering the Ceramics. In Ancient Psychoactive Substances, edited by Scott M. Fitzpatrick, pp. 198-233. University Press of Florida, Gainesville.

Lubinski, Patrick M., and Greg C. Burtchard

2005 Fryingpan Rockshelter (45PI43): A Subalpine Fauna in Mount Rainier National Park. Archaeology in Washington 11:35-52.

Lyons, Natasha, Anna Marie Prentiss, Sandra Peacock, and Bill Angelbeck

2018 Some Like It Hot: Exploring the Archaeobotany of Roasting Features in Southern British Columbia. Inlet: Contributions to Archaeology 1:1-13.

Matson, R. G.

1976 Artifact Summary. In The Glenrose Cannery Site, edited by R. G. Matson, pp. 104-184. Archaeological Survey of Canada Paper No. 52. National Museums of Canada, Ottawa.

Milanich, Jerald T.

1979 Origins and Prehistoric Distributions of Black Drink and the Ceremonial Shell Drinking Cup. In Black Drink: A Native American Tea, edited by Charles M. Hudson, pp. 83-119. University of Georgia Press, Athens.

Mitchell, Donald H.

1963 Esilao - A Pit House Village in the Fraser Canyon, British Columbia. Master's thesis, Department of Anthropology and Sociology, University of British Columbia, Vancouver.

Moerman, Daniel E.

1998 Native American Ethnobotany. Timber Press, Portland, Oregon.

Moss, Madonna L.

2011 Northwest Coast: Archaeology as Deep History. SAA Contemporary Perspectives. Society for American Archaeology, Washington, DC.

Nelson, Nancy J.

2000 The Umpqua Eden Site: Their Smoking Pipes and Tobacco Cultivation. Master's thesis, Oregon State University, Corvallis.

Niemeyer, Hermann M., Patricio de Souza, Conrado Camilo, and Javier Echeverría

2018 Chemical Evidence of Prehistoric Passive Tobacco Consumption by a Human Perinate (Early Formative Period, South-Central Andes). Journal of Archaeological Science 100:130-138. DOI:10.1016/j.jas.2018. 10.010 .

Parish, Roberta, Ray Coupé, and Dennis Lloyd (editors)

1999 Plants of Southern Interior British Columbia and the Inland Northwest. Lone Pine, Vancouver.

Pavesic, Max G.

1985 Cache Blades and Turkey Tails: Piecing Together the
Western Idaho Archaic Burial Complex. In Stone Tool Analysis: Essays in Honor of Don E. Crabtree, edited by Mark G. Plew, James C. Woods, and Max G. Pavesic, pp. 55-89. University of New Mexico Press, Albuquerque. Phillips, Patricia Whereat

2016 History and Modern Use of Sacred Tobacco on the Central and Southern Oregon Coast. In Perspectives on the Archaeology of Pipes, Tobacco and other Smoke Plants in the Ancient Americas, edited by Elizabeth A. Bollwerk and Shannon Tushingham, pp. 199210. Springer, Cham, Switzerland.

Pluskal, Tomáš, Sandra Castillo, Alejandro Villar-Briones, and Matej Orešič

2010 MZmine 2: Modular Framework for Processing, Visualizing, and Analyzing Mass Spectrometry-Based Molecular Profile Data. BMC Bioinformatics 11(1):395.

Pouley, John Oliver

2001 Archaeological Investigations at the Ridge Bottom Village, Site 45GR27, Moses Lake, Washington. Master's thesis, Department of Anthropology, Washington State University, Pullman.

Rafferty, Sean M.

2002 Identification of Nicotine by Gas Chromatography/ Mass Spectroscopy Analysis of Smoking Pipe Residue. Journal of Archaeological Science 29:897-907. DOI:10.1006/jasc.2001.0747.

2006 Evidence of Early Tobacco in Northeastern North America? Journal of Archaeological Science 33:453458. DOI:10.1016/j.jas.2005.08.006.

Rafferty, Sean M., Igor Lednev, Kelly Virkler, and Zuzana Chovanec

2012 Current Research on Smoking Pipe Residues. Journal of Archaeological Science 39:1951-1959. DOI:10. 1016/j.jas.2012.02.001.

Reimer, Paula J., Edouard Bard, Alex Bayliss, J. Warren Beck, Paul G. Blackwell, Christopher Bronk Ramsey, Caitlin E. Buck, et al.

2013 IntCal13 and Marine13 Radiocarbon Age Calibration Curves 0-50,000 Years Cal BP. Radiocarbon 55:1869-1887. DOI:10.2458/azu_js_rc.55.16947.

Rezvani, Amir H, and Edward D. Levin

2001 Cognitive Effects of Nicotine. Biological Psychiatry 49:258-267. DOI:10.1016/S0006-3223(00)01094-5.

Rice, David G.

1965 Archaeological Test Excavations in Fryingpan Rockshelter, Mount Rainier National Park. Report of Investigations. Laboratory of Anthropology, Washington State University, Pullman.

Rowley, Susan

2013 The Reciprocal Research Network: The Development Process. Museum Anthropology Review 7(1-2):22-43.

Schultes, Richard Evans, Albert Hofmann, and Christian Rätsch 2001 Plants of the Gods: Their Sacred, Healing, and Hallucinogenic Powers. Healing Arts Press, Rochester, Vermont.

Schulting, Rick J.

1995 Mortuary Variability and Status Differentiation on the Columbia-Fraser Plateau. Archaeology Press, Simon Fraser University, Burnaby, British Columbia.

Seinfeld, Daniel M.

2018 Intoxication Rituals and Gender among the Ancient Maya. In Ancient Psychoactive Substances, edited by Scott M. Fitzpatrick, pp. 176-197. University Press of Florida, Gainesville.

Setchell, William Albert

1921 Aboriginal Tobaccos. American Anthropologist 23:397-415. 
Snyder, Charles M.

2016 Restoring Traditional Tobacco Knowledge: Health Implications and Risk Factors of Tobacco Use and Nicotine Addiction. In Perspectives on the Archaeology of Pipes, Tobacco and other Smoke Plants in the Ancient Americas, edited by Elizabeth Anne Bollwerk and Shannon Tushingham, pp. 183-197. Springer, Cham, Switzerland.

Stuiver, Minze, Paula J. Reimer, and Ron W. Reimer

2005 CALIB 5.0 [WWW Program and Documentation]. Electronic document, http://calib.org, accessed September $1,2020$.

Sullivan, Roger J., Edward H. Hagen, and Peter Hammerstein 2008 Revealing the Paradox of Drug Reward in Human Evolution. Proceedings of the Royal Society B: Biological Sciences 275:1231-1241.

Taylor, Roy L., and Sylvia Taylor

1981 Taxus brevifolia in British Columbia. Davidsonia 12 (4):89-94.

Teit, James A.

1900 The Thompson Indians of British Columbia. Edited by Franz Boas. Memoirs of the American Museum of Natural History Vol. 2, Pt. 4. G. P. Putnam's Sons, New York.

Teit, James

1909 The Shuswap. Edited by Franz Boas. Memoirs of the American Museum of Natural History Vol. 4, Pt. 7. G. E. Stechert, New York.

Torres, Constantino Manuel

1996 Archaeological Evidence for the Antiquity of Psychoactive Plant Use in the Central Andes. Annuli dei Musei Civici Rovereto 11:291-326.

Turner, Nancy J.

1998 Plant Technology of First Peoples in British Columbia. 2nd ed. University of British Columbia Press, Vancouver.

2014 Ancient Pathways, Ancestral Knowledge: Ethnobotany and Ecological Wisdom of Indigenous Peoples of Northwestern North America. McGill-Queen's University Press, Montreal.

Turner, Nancy J., and Roy L. Taylor

1972 A Review of the Northwest Coast Tobacco Mystery. Syesis 5:249-257.

Tushingham, Shannon, Dominique Ardura, Jelmer W. Eerkens, Mine Palazoglu, Sevini Shahbaz, and Oliver Fiehn

2013 Hunter-Gatherer Tobacco Smoking: Earliest
Evidence from the Pacific Northwest Coast of North America. Journal of Archaeological Science 40:13971407. DOI:10.1016/j.jas.2012.09.019.

Tushingham, Shannon, Charles M. Snyder, Korey J. Brownstein, William J. Damitio, and David R. Gang

2018 Biomolecular Archaeology Reveals Ancient Origins of Indigenous Tobacco Smoking in North American Plateau. PNAS 115:11742-11747. DOI:10.1073/pnas. 1813796115.

USDA, NRCS

2021 Salvia sonomensis. The PLANTS Database National Plant Data Team, Greensboro, North Carolina. Electronic document, https://plants.usda.gov/core/profile? symbol=SASO, accessed January 5, 2021.

Van de Peer, Yves

2015 Draw Venn Diagram: Calculate and Draw Custom Venn Diagrams. Electronic document, http:/ bioinformatics.psb.ugent.be/webtools/Venn/, accessed December 1, 2020.

VanPool, Christine S.

2009 The Signs of the Sacred: Identifying Shamans Using Archaeological Evidence. Journal of Anthropological Archaeology 28:177-190. DOI:10.1016/j.jaa.2009.02. 003.

Washburn, Dorothy K., William N. Washburn, Petia A. Shipkova, and Mary Ann Pelleymounter

2014 Chemical Analysis of Cacao Residues in Archaeological Ceramics from North America: Considerations of Contamination, Sample Size and Systematic Controls. Journal of Archaeological Science 50:191-207.

Winter, Joseph C.

2000 Botanical Description of the North American Tobacco Species. In Tobacco Use by Native North Americans: Sacred Smoke and Silent Killer, edited by Joseph C. Winter, pp. 87-127. University of Oklahoma Press, Norman.

Zagorevski, Dmitri V., and Jennifer A. Loughmiller-Newman 2012 The Detection of Nicotine in a Late Mayan Period Flask by Gas Chromatography and Liquid Chromatography Mass Spectrometry Methods: Detection of Nicotine in a Late Mayan Period Flask. Rapid Communications in Mass Spectrometry 26:403-411. DOI:10.1002/rcm.5339.

Submitted September 29, 2020; Revised February 10, 2021;

Accepted February 10, 2021 